\title{
CORRIGENDUM
}

\section{Sampling scheme for pyrethroids on multiple surfaces on commercial aircrafts}

KRISHNAN R. MOHAN AND CLIFFORD P. WEISEL

Journal of Exposure Science and Environmental Epidemiology (2010) 20, 570; doi:10.1038/jes.2009.70

Correction to: Journal of Exposure Science and Environmental Epidemiology (2010) 20, 320-325; doi:10.1038/jes.2009.26; published online 16 September 2009

After the above article was published online, one of the authors noticed that the following information had been omitted from the Acknowledgements section:

"This research was supported in part by the NIEHSsponsored UMDNJ Center for Environmental Exposures and Disease, Grant NIEHS P30ES005022."

The full Acknowledgements section should therefore read as follows:
"This study was supported by the US Federal Aviation Administration (FAA) Office of Aerospace Medicine through the Air Transportation Center of Excellence for Airliner Cabin Environment Research (ACER), Cooperative Agreement 04-C-ACE-UMDNJ. Although the FAA has sponsored this project, it neither endorses nor rejects the findings of this research. This research was supported in part by the NIEHS-sponsored UMDNJ Center for Environmental Exposures and Disease, Grant NIEHS P30ES005022." 